Revista Temas Socio Jurídicos

Vol. $36 \mathrm{~N}^{\circ} 73$ Julio - Diciembre de 2017

pp. $153-175$

ISSN 0120-8578

ISSN electrónico: 2590-8901

\title{
O EXERCÍCIO DO CONTROLE DE CONSTITUCIONALIDADE NO BRASIL. OS PRINCÍPIOS DA SEGURANÇA JURÍDICA, DA CONFIANÇA E A POSSIBILIDADE DE MUTABILIDADE DAS DECISÕES JUDICIAIS EM MATÉRIA TRIBUTÁRIA BEM COMO, DE MODULAÇÃO E ATRIBUIÇÃO DE EFEITOS PROSPECTIVOS ÀS DECISÕES JUDICIAIS DO STF
}

\author{
Ivo Jose Kunzler* \\ Recibido: Enero 21 de 2017 \\ Aprobado: Agosto 20 de 2017
}

\section{RESUMO}

Com a presente análise, se pretende investigar a origem e o fundamento teórico das diversas escolas sobre a interpretação do Direito Constitucional, e o exercício do controle de constitucionalidade em matérias tributária no Brasil. Analisa-se ainda, as razões da modulação dos efeitos da decisão pelo Supremo Tribunal Federal, quando isso ocorre por razões de aplicação do princípio da segurança jurídica ou de excepcional interesse social

Palavras-Chaves: controle de constitucionalidade; princípio da segurança jurídica; mutabilidade; interpretação.

\footnotetext{
* Advogado; Graduado em Ciências Jurídicas e Sociais pela UFPEL; Formação complementar em Filosofia pela UFPEL e Ciência Econômicas - Economia pela UNISINOS; Especialista em Direito Tributário pelo IBET - Instituto Brasileira de Direito Tributário; Especialista em Gestão Ambiental pela FEEVALE; Mestre em Direito Tributário e Constitucional pela UNISC; Estudante do programa de Doutorado na UBA em Direito Constitucional.E-mail: ivokunzler@kunzleradvogados.com.br
} 


\title{
EL EJERCICIO DE CONTROL DE
}

CONSTITUCIONALIDAD EN BRASIL. LOS PRINCIPIOS DE LA SEGURIDAD JURÍDICA, DE LA CONFIANZA Y LA POSIBILIDAD DE MUTABILIDAD DE LAS DECISIONES JUDICIALES EN MATERIA TRIBUTARIA BIEN COMO DE MODULACIÓN Y ATRIBUCIÓN DE EFECTOS PROSPECTIVOS A LAS DECISIONES JUDICIALES DEL SUPREMO TRIBUNAL FEDERAL (STF)

\section{RESUMEN}

Con este análisis, se tiene la intención de investigar el origen y el fundamento teórico de varias escuelas de la interpretación de la ley constitucional, y el ejercicio del control jurisdiccional en materia fiscal en Brasil. Se analiza también, las razones de la modulación de los efectos de la decisión del Supremo Tribunal Federal, cuando esto ocurre mediante la aplicación del principio de la seguridad jurídica o de interés social excepcional

Palabras clave: control de constitucionalidad; principio de seguridad jurídica; mutabilidad; interpretación.

\section{THE EXERCISE OF CONSTITUTIONAL CONTROL IN BRAZIL. THE PRINCIPLES OF LEGAL CERTAINTY, TRUST AND POSSIBILITY OF MUTABILITY OF JUDICIAL DECISIONS IN TAX MATTERS, AS WELL AS OF MODULATION AND ATTRIBUTION OF PROSPECTIVE EFFECTS TO THE JUDICIAL DECISIONS OF THE FEDERAL SUPREME COURT}

\begin{abstract}
This analysis focuses on the origin and the theoretical foundation of several schools of interpretation of constitutional law, and the exercise of judicial control in taxation matters in Brazil. It also refers to the reasons for the modulation of the effects of the decision of the Federal Supreme Court, when it involves the application of the principle of legal certainty or exceptional social interest.
\end{abstract}

Keywords: Constitutional control, principle of legal certainty, mutability, legal interpretation. 


\section{INTRODUÇÃO - PONTUANDOA POLÊMICA}

A relevância da análise do acórdão resultante da interpretação que o Supremo Tribunal Federal, última instância judicial de prestação jurisdição constitucional no Brasil, por sua composição plenária de julgamento, deu em sede de controle difuso de constitucionalidade, à norma constitucional que disciplina o aproveitamento dos créditos do IPI - Imposto sobre Produtos Industrializados, tributados com alíquota (zero) na entrada - aquisição da matéria prima, insumos. Entre várias possibilidades, pretende-se analisar e compreender melhor porque o Pleno do Supremo Tribunal Federal, não aceitou a sugestão do Ministro Lewandowski, que apresentou questão de ordem no referido julgamento, no sentido de modular os efeitos da decisão, para atribuir efeitos prospectivos, ante o princípio da segurança jurídica. A norma infraconstitucional sob judice está nos artigos 179 a 198 do Decreto número 4.544 de 26/12/2002, em combinação com o artigo 153 , IV, § $3^{\circ}$, inciso III da Constituição Federal de 1988, que afirma o princípio da não cumulatividade do Imposto sobre Produtos Industrializados - IPI.

Esta análise de decisão da Corte Constitucional brasileira será medida e criticada a partir de várias teorias do direito, que introduzimos de maneira resumida no pensamento do professor ALFONSÍN, quando ele comenta sobre o mesmo assunto, se referindo à mesma polêmica na Argentina: "La discusión acerca de quién debe ser el defensor de la Constitución no es nueva ni mucho menos, y ha contado con exponentes de primera línea em todo el mundo: basta con ejemplificarlo con el célebre debate entre Han Kelsen y Carl Schmitt en las primeras décadas del siglo XX. Al mismo tiempo, em problema de cómo debe desarrollarse ese control tuvo, en nuestro país, exponentes de la talla de Alberdi Y Sarmiento $^{11}$

A decisão em análise, foi proferida nos autos do Recurso Extraordinário, número 370.682 (0riginário do Estado de Santa Catarina). Longe de ter se pacificado o debate sobre o tema com a decisão em comento, o que se observa, é que o tema está aquecido em todos os círculos de estudo, e vêm suscitando ainda debate acalorado da doutrina e da jurisprudência sobre a interpretação dada pela mais alta corte de jurisdição constitucional do país, e em sede de controle difuso de constitucionalidade, isto é, em Recurso Extraordinário ${ }^{2}$, como se refere

1 ALFONSÍN, Marcelo Alberto López. Sobre el principio de supremacía y una pregunta reiterada: ?Quién debe ejercer el control de constitucionalidad en Argentina?. in: artigo oferecido pelo professor para estudos por ocasião das aulas do 3o. Módulo do Curso de Doutorado na UBA.

2 DERZI, Mizabel Abreu Machado. A Irretroatividade do Direito, a Proteção da Confiança, a Boa-fé e o RE no. 370.682 - SC. in Revista Dialética. São Paulo, 11. Volume. 2007, p. 299. 
Derzi. Segundo a mais autorizada doutrina sobre o tema, no caso o STF deixou de observar um conjunto de princípios jurídicos inarredáveis, conforme referência feita no teor da decisão pelo Ministro Lewandowski, e entre estes, o mais importante, o da segurança jurídica, e também rompeu com a confiança que a sociedade brasileira depositava no STF e não observou a boa-fé que as empresas que se conduziram pela pacificada orientação jurisprudencial anterior, adotada pela Suprema Corte brasileira por força de decisões proferidas no Pleno desta Corte, já ha mais de uma dezena de anos.

Antes de ingressar na análise do caso concreto, importante estabelecer os parâmetros de competência e o significado da jurisdição constitucional brasileira, e como se dá o controle de constitucionalidade no Brasil. Neste sentido lógico, conforme Leal, é obrigatória a observação de que o Estado brasileiro é consequência do processo revolucionário que instaurou o primeiro Estado Democrático de Direito, dentro do triunfo burguês da Revolução Francesa ${ }^{3}$ de 1789 , e por consequência, é portador do ideário surgido no processo da independência dos Estados Unidos da América e da Revolução Francesa. Dois movimentos revolucionários do final do Século XIX, que influenciaram os modelos constitucionais do mundo inteiro. Surgiu assim o Estado Liberal com todas as suas características e feições, que passou a ser referencial político às Nações que acabaram de se libertar da condição de colônias, Repúblicas ou Monarquias. Neste passo, preciso que se compreenda que um dos principais efeitos irradiadores do Estado Democrático de Direito é a segurança jurídica ${ }^{4}$ depositado na lei, conforme Martins. Um Estado que substitui a figura do Rei pela Lei, e por consequência confere a esta expressão de obrigatoriedade e governo sobre as pessoas. Assim, Martins, descreve este importante sentido da Lei:
É o direito a segurança que define a sustentação, firmeza e eficácia do ordenamento jurídico. Exige previsibilidade e certeza em relação aos efeitos jurídicos dos atos normativos a que a sociedade deve obediência, principalmente para o contribuinte da obrigação tributária.

Colocado nestes termos, verifica-se então qual origem e as características da interpretação constitucional brasileira, e quais as fontes teóricas da jurisdição constitucional, para depois se tirar uma

3 LEAL, Mônia C. Hennig. Jurisdição Constitucional Aberta. Reflexões sobre a Legitimidade e os Limites da Jurisdição Constitucional na Ordem Democrática. Rio de Janeiro, Editora Lumen Juris. 2007, p. 5.

4 MARTINS, Ives Gandra da Silva; RODRIGUES, Marilene Talarico Martins. Efeitos das Decisões do STF, em Matéria Tributária, em Situações de Mudança de Jurisprudência (Créditos de IPI, nas Hipóteses de Alíquota Zero). in Revista Dialética. São Paulo, $11^{\circ}$. Volume. 2007, p. 184.

5 Ibidem, p. 185. 
conclusão prática e teórica da aplicação da norma constitucional no controle da constitucionalidade, na forma como foi aplicada ao caso. É inegável que para se entender a origem do artigo 103 da Constituição Federal do Brasil, e a escolha do sistema abstrato ou concentrado, e o artigo 102 inciso III da Constituição, que acolheu também a hipótese em que o STF tem competência para declarar a inconstitucionalidade em grau de recurso, isto é, em controle difuso da constitucionalidade, que é nosso caso em exame, é preciso verificar de onde vieram as influências teóricas desta criação interpretativa. Diante da citação e referência feita pelo professor ALFONSÍN acima, comecemos abordando as teorias de Karl Schmitt e Kelsen.

\section{O ADVENTO DO DIREITO CONSTITUCIONAL E DOS TRIBUNAIS CONSTITUCIONAIS. O DEBATE TEÓRICO ENTRE CARL SCHMITT (ALEMANHA) E HANS KELSEN (ÁUSTRIA).A EUROPA E O PRIMEIRO PÓS-GUERRA.}

Até o advento do chamado Estado Social de Direito no início do século $\mathrm{XX}$, as constituições constituem-se apenas num documento eminentemente jurídico formal, cuja prerrogativa maior era a imposição de limites ao Estado e a garantia dos direitos individuais negativos, conforme preleciona Leal. ${ }^{6}$ Nestes tempos, cabia à Constituição tão somente estabelecer a estrutura básica do Estado, com seus poderes e suas respectivas competências, proclamando, na relação indivíduoEstado, a essência dos direitos fundamentais relativos à capacidade civil e política dos governados, os assim chamados direitos de liberdades. Houve grandes debates a cerca da instalação de um Tribunal Constitucional no "Sagrado Império da Nação alemã", e no Congresso de Viena, Prússia e Áustria foi realizado um acordo de instituição de um Tribunal Federal com competência para dirimir conflitos dos membros da União prussiana entre si e decidir os recursos ou reclamações opostas pelos cidadãos contra ofensa às Constituições estaduais. ${ }^{8}$ No entanto, foi na Constituição de 1849 que aparece o primeiro projeto concreto de organização de uma jurisdição constitucional prussiana, e reflete a tendência centralizadora, confiando-se a defesa da ordem constitucional ao Tribunal do Império. Esta Constituição não chegou a ser promulgada. ${ }^{9}$ A justiça constitucional somente teve espaço na Europa a partir do pós-guerra de 1919 no tempo de Weimar na Alemanha

6 LEAL, Mônia C. Hennig. Jurisdição Constitucional Aberta. Reflexões sobre a Legitimidade e os Limites da Jurisdição Constitucional na Ordem Democrática. Rio de Janeiro, Editora Lumen Juris. 2007, p. 29.

7 Ibidem, p. 30.

8 MENDES, Gilmar. Jurisdição Constitucional. O Controle abstrato de Normas no Brasil e na Alemanha. São Paulo, Editora Saraiva, $3^{a}$. Edição, 1999, p. 7.

9 Ibidem, p. 7. 
republicana, e foi dominada por duas vias teóricas principais, marcadas por uma substancial dicotomia em seu modelo, descritas por Leal, da seguinte forma:
A Constituição da República de Weimar instituiu, em seu texto, um Tribunal ao qual foram confiados os conflitos entre os poderes constitucionais, especialmente aqueles condizentes com a organização federal. Já o segundo sistema, que veio a consagrar-se definitivamente, sobretudo no segundo pós- guerra, no meio europeu - apesar das modificações sofridas, como veremos - é o sistema austríaco, idealizado por Kelsen e incorporado à Constituição daquele país em $1920 .^{10}$

Destaca ainda a autora, acerca da natureza do controle de constitucionalidade que se desenvolveu, de observar-se, no que tange à conformação do controle de constitucionalidade na Europa, o acirrado debate que se estabeleceu, no final da década de 1920, em meio às discussões sobre a Constituição de Weimar, entre Hans Kelsen e Carl Schmitt no sentido de determinar a quem melhor caberia a competência de zelar pela Constituição. ${ }^{11}$ E segundo a autora este debate se deu em função de que:

Para Schmitt, o Führer do Reich alemão é quem deveria ser o verdadeiro guardião da Constituição, pois os tribunais formados por magistrados não apresentariam as condições necessárias para a manutenção da unidade do sistema político e jurídico. Já o chefe do Executivo, por outro lado, uma vez eleito por todo o povo, expressaria a vontade da maioria e, portanto, estaria mais qualificado, em termos de legitimidade, para ser o defensor da Constituição. ${ }^{12}$

Neste contexto Schmitt pretendia que o judiciário se tornasse extremamente dependente do poder executivo, e convertendo-se em organismo fortemente politizado. Se por um lado defendia que era atribuição do Füher a manutenção da ordem e das instituições, inclusive da Constituição, negando em grande parte a divisão liberal dos três poderes, por outro lado, tinha o entendimento de que o jurista alemão, isto é, o Tribunal deveria ter apenas a tarefa de única e exclusivamente fazer a subsunção de certos fatos aos pressupostos normativos previamente postos pelo legislador ${ }^{13}$, retornando desta forma, a teoria 
interpretativa literal do tempo do velho Código de Napoleão. Segundo o entendimento, a análise e a apreciação da constitucionalidade das leis, não se enquadra nos limites desta concepção restrita, uma vez que tal atividade consistira tão somente, em se verificar a compatibilidade entre a lei e a Constituição, o que segundo Schmitt, ultrapassava e desvirtuava a função reservada aos magistrados, já que tal ato não passava de uma comparação entre normas. Como Schmitt somente considerava atividade jurisdicional aqueles atos que houvesse subsunção de fato a lei, e a atividade de verificação da constitucionalidade de determinada lei não tinha esta natureza, não era atividade sujeita aos magistrados, e sim tarefa conferida aos políticos, e em especial ao poder executivo.

De outro lado, Hans Kelsen, o representante do chamado Círculo de Viena, criticou radicalmente as formulações de Schmitt, dizendo que se aquele entendia que à atividade política compreendia proferir uma decisão, então estaria presente em cada sentença de magistrado um elemento de decisão e de exercício de poder, e que a diferença de índole política de que se revestiria a aplicação de qualquer lei e o controle de constitucionalidade puramente, era apenas de natureza quantitativa e não propriamente qualitativa. ${ }^{14}$ Do debate entre os dois representantes das teorias acima - Schmitt pela Alemanha e Kelsen pela Áustria, se chegou à conclusão de que não havia motivos da não existência de órgão do poder judiciário específico, encarregado de executar a tarefa de controle de constitucionalidade jurisdicional, e esta foi a ideia que ao final prevaleceu, ao menos como modelo de referência. ${ }^{15}$ Nasce deste debate a perspectiva do controle concentrado de constitucionalidade, numa variante muito original do que temos hoje no Brasil. Percorrendo um caminho diverso, o sistema de controle difuso de constitucionalidade, teve origem na Independência dos Estados Unidos da América, e suas razões estão assentadas no próprio processo de independência, influenciado pelo modelo constitucional da Inglaterra, e não pelo modelo Francês.

Em comentário, o professor ALFONSÍN, cita o pensamento de SARMIENTO, referendando seus "COMENTÁRIOS", sobre a Corte Norte Americana, segundo que "el poder judicial es independente de los otros poderes, y coexistente com ellos. Su oficio es aplicar las leyes, en todos los casos contenciosos: la Constitución es la ley suprema, luego la aplicación práctica que de sus disposiciones hagan los otros poderes recae bajo la jurisdicción y el fallo del Supremo poder judicial, en los

14 Ibidem, p. 45

15 LEAL, Op. Cit.p. 45. 
casos que se reputen agredidos derechos que motiven acción, y pidan amparo". ${ }^{16}$

\section{O CONTROLE DIFUSO DA CONSTITUCIONALIDADE NO BRASIL. A INDEPENDÊNCIA DOS ESTADOS UNIDOS DA AMÉRICA E SUAS INFLUÊNCIAS NA CONSTITUIÇÃO BRASILEIRA}

Se o sistema de controle da constitucionalidade europeu, especialmente na Alemanha e na Áustria e nos países continentais que seguiram esta experiência, foi o de controle concentrado de constitucionalidade, por sua vez no sistema americano influenciado pelo sistema do Common Law da Inglaterra, se diferenciou essencialmente pela Judicial Review americana - de caráter difuso - em aspectos decisivos, pois aquele confia a um único tribunal, o Tribunal Constitucional, a tarefa de preservar a Constitucionalidade. No sistema americano o controle pode ser realizado por vários Tribunais, e de forma difusa. No ensinamento que Leciona sobre o sistema constitucional alemão e austríaco, Leal assevera:

Essa variação esconde, todavia, uma profunda significação por detrás de sua simples aparência prática: se a desconfiança com relação aos juízes levou, na França, a radicalização do controle de constitucionalidade - onde o mesmo é feito em caráter preventivo, por um tribunal de natureza política - essa ,mesma desconfiança levou, em outro nível, a exclusão dos juízes ordinários na maioria dos países da Europa, através do estabelecimento de Tribunais Constitucionais que se localizam fora da estrutura do Poder Judiciário. Assim, na Europa, nem sequer chegou a se colocar a opção entre um sistema concentrado e o sistema difuso, sendo que a decisão pelo primeiro deveu-se, portanto, muito mais a questões de ordem política do que a aspectos técnicos (como a ausência do stare decisis, por exemplo, que não permitiria a tais decisões a extensão dos efeitos erga omnes).

Em face da desconfiança com relação ao Poder Judiciário, Kelsen idealizou o controle de constitucionalidade como uma função não

16 ALFONSÍN, Marcelo Alberto López. Sobre el principio de supremacía y una pregunta reiterada: ?Quién debe ejercer el control de constitucionalidad en Argentina?. in: artigo oferecido pelo professor para estudos por ocasião das aulas do 3o. Módulo do Curso de Doutorado na UBA 
propriamente judicial, sendo de "legislação negativa", em que cabe, a este órgão, analisar tão somente o problema (puramente abstrato) de compatibilidade lógica ente a lei e a norma constitucional. No segundo pós-guerra, houve um afastamento por parte dos Tribunais Constitucionais europeus do modelo de controle concentrado proposto por inicialmente por Kelsen, o que fez com que os Tribunais passassem a incorporar e adquirir novas dimensões e competências, além daquela inicial. Prevaleceu na Europa inicialmente, a exemplo da Itália, e inclusive na Alemanha de Carl Schmitt, o sistema Kelseniano. Tal efeito veio segundo o ensinamento de Leal, em sua obra "Jurisdição Constitucional Aberta" do seguinte fato:

Pode-se destacar como elemento determinante para tal decisão, o fato de que, em ambos os países, deu-se a experiência de se ter no legislador a maior ameaça a liberdade, ao valer-se da tradicional concepção (formal) de Estado de Direito, realidade na qual a lei passou a ser instrumento para a prática de injustiças, ao invés de mecanismo de garantia contra o arbítrio. Foi esta experiência por sua vez, que em parte, forçou os constituintes a adotarem a estratégia dos Tribunais Constitucionais como instância de preservação dos valores supremos e tendencialmente inalteráveis, insculpidos no texto constitucional. ${ }^{18}$

Diante do fracasso do sistema weimariano de justiça constitucional, dada sua utilização desvirtuada pelo nazismo, a Alemanha, por exemplo, adotou em sua Constituição de 1949, a Lei Fundamental de Bonn (Grundgesetz), ainda que com algumas variações, era originária do sistema kelseniano. ${ }^{19}$ Afirmado estes pontos de divergência, transparecem algumas diferenças de natureza nítida, do que pretendiam os fundadores das duas teorias. A tendência inicial de Carl Schmitt era defender a ideia de um Tribunal Constitucional com natureza nitidamente política, referendado no poder executivo diretamente eleito ou legitimado pela maioria, pelo sistema eleitoral. Não podia nesta lógica este tribunal se revestir de natureza jurídica. Kelsen, por outro lado, defendia um Tribunal Constitucional, que deveria proferir decisões sobre a constitucionalidade de leis, e em tal atividade a sua diferença em relação a qualquer outra atividade jurisdicional era apenas de quantidade. Ao que se percebe, está mesmo presente no debate a questão acerca de definir a que face do poder estatal tal tribunal deveria obediência, e tudo decorria do processo político em curso na Europa. De alguma forma, o debate entre os dois juristas e filósofos era um reflexo 
de duas escolas jusfilosóficas em formação, uma na Alemanha, a escola de Frankfurt e outra mais experiente e já com algum tempo de estudos na Áustria, o Círculo de Viena.

Os Estados Unidos da América vindos de um processo revolucionário distinto daquele acontecido na Europa continental e de influência da Revolução Francesa de 1789. Trouxe consigo a experiência e os efeitos da revolução na Inglaterra, que fizera a sua revolução quase um século antes da francesa, e teve inclusive outra relação entre parlamento e Estado. Dali os americanos do norte construíram seu sistema constitucional calçado no Common Law, o que resultou num controle difuso de constitucionalidade das leis. Os efeitos dos dois sistemas de controle da constitucionalidade estão na Constituição Federal de 1988 no Brasil. A. influência do sistema de controle constitucional americano do Common Law e também o sistema europeu foram acolhidos pelo sistema brasileiros de controle de constitucionalidade.

\section{AS DUAS ESCOLAS DE PENSAMENTO:O NEOPOSITIVISMO LÓGICO DE ORIGEM NO PENSAMENTO KANTIANO E O CONSTITUCIONALISMO DECORRENTE DA ESCOLA DE FRANKFURT - HABERMAS E GADAMER}

É inegável o fato de que durante largo período, senão quase todo o século $\mathrm{XX}$, a corrente kelseniana de controle da constitucionalidade foi vencedora, senão pelo menos majoritária. Os motivos de tal afirmação, certamente estão ligados aos fatos políticos que envolveram a Europa continental na primeira metade do século (nazismo), e também à fragilidade democrática existente nos países de desenvolvimento tardio (ditaduras). De outro lado, igualmente se pode afirmar que o movimento constitucionalista contrário a teoria kelseniana nunca esmoreceu, nem deixou de buscar sua afirmação diferenciadora dentro de um processo que começou muito antes de surgir a escola de Frankfurt. Em verdade, um modelo diferente de teoria constitucional já nascia dos debates teóricos entre Ferdinand Lassale ${ }^{20}$, e seus contemporâneos. No entanto, este debate se estruturou a e desenvolveu mais intensamente a partir de dois dos principais jusfilósofos alemães, Hans-Georg Gadamer e Jürgen Habermas. Destes dois importantes filósofos advieram duas formas de interpretar e ver o direito constitucional, o substancialismo e o procedimentalismo. ${ }^{21}$ Além das formulações teóricas citadas, também

20 LASSALE, Ferdinand. A Essência da Constituição. Rio de Janeiro, Editora Lumen Juris, 2000, p. 6. 21 STRECK, Lenio Luiz. Verdade e Consenso. Constituição, Hermenêutica e Teorias Discursivas da Possibilidade à Necessidade de Respostas Corretas em Direito. Rio de Janeiro, Editora Lumen Juris, 2007, p. 24 . 
deixou suas influências e fez discípulos o constitucionalista Konrad $\mathrm{Hesse}^{22}$, que dos resultados do diálogo teórico e do debate com a teoria de Ferdinand Lassale, acabou por fazer prevalecer a sua ideia, da força normativa das constituições, e seu entendimento fez escola entre nós com os ensinamentos de Peter Haberle ${ }^{23}$, que se tornou um de seus principais discípulos. Os teóricos do neopositivismo lógico têm a linguagem como instrumento por excelência do saber científico. Diziam eles que a própria linguagem deveria servir de modelo de controle dos conhecimentos por ela produzidos. Chegam a proposições afirmativas como esta: compor um discurso científico é verter em linguagem rigorosa os dados do mundo, de tal sorte que ali onde não houver precisão linguística não poderá haver ciência. ${ }^{24}$ Mais adiante afirma o autor:

Por outro lado, não é difícil identificar os fundadores do movimento: Rudolf Carnap, Hans Hahn e Otto Neurath, sob a coordenação indiscutível e brilhante de Moritz Schlick, de quem já falamos. Ludwig Wittgenstein não chegou a pertencer ao grupo, entretanto seu livro Tractatus lógico-philosophicus influenciou diretamente os integrantes do movimento, havendo quem afirme que sem as idéias contidas nesses escritos, os neopositivistas jamais teriam alcançado os níveis de profundidade a que chegaram. Essa obra apareceu em 1922, com introdução de Bertrand Russel, e na proposição 5.6 está dito que "os limites da linguagem são os limites do mundo".

Esta nova concepção, dando origem à filosofia da linguagem ordinária, provocou aquilo que veio a chamar-se "giro-linguístico", movimento dentro do qual se estaria cada vez mais imerso, cada vez com maior intensidade, segundo pensa (Carvalho, 2008, p. 2125), que no Brasil é o principal, seguidor desta linha de interpretação do direito. Pelas mãos da escola alemã, e de todo o processo de construção teórica do século XIX, chegou até os leitores e estudantes entre nós os ensinamentos do professor Jürgen Habermas, pelo trabalho teórico desenvolvido por Leal, ${ }^{26}$ o que podemos observar:

22 HESSE, Konrad. 2 A força normativa da Constituição. Tradução de Gilmar Ferreira Mendes. Porto Alegre, Sergio Fabris Editores.1991, p.14.

23 HÀBERLE, Peter. Os Problemas da Verdade no Estado Constitucional. Tradução de Urbano Carvelli. Porto Alegre, Sergio Antonio Fabris Editor, p. 22.

24 BARROS CARVALHO, Paulo. Direito Tributário, Linguagem e Método. São Paulo. Editora Noeses, 2008 , p. 21.

25 BARROS CARVAlHO, Paulo. Direito Tributário, Linguagem e Método. São Paulo. Editora Noeses, 2008 , p. 25.

26 LEAL, Rogério Gesta. O Estado-Juiz na Democracia Contemporânea. Uma Perspectiva Procedimentalista, Porto Alegre, 2007, p. 84. 
Significa dizer, com Habermas, que a Constituição determina procedimentos políticos, segundo os quais os cidadãos, assumindo seu direito de autodeterminação, podem perseguir cooperativamente o projeto de produzir condições justas de vida. [...] A responsabilidade para a correção de rumos em tais situações resta compartilhada em todo o tecido societário, envolvendo tanto a cidadania como suas instituições representativas, assim como o mercado seja pela via da revolução, resistência civil, seja pela via legislativa, administrativa e judicial, porém, não perdendo de vista que a tarefa fulcral não é a de substituir formas de poder autoritárias por outras de iguais feições, marcadas pela natureza corporativa e unilateral que possuem, ma efetivamente resgatar a autonomia e o fortalecimento dos espaços públicos de deliberação política. ${ }^{27}$

Observa-se com esta descrição, que a questão para o movimento procedimentalista é fortalecer o processo de realização das liberdades, e desta forma a garantia da legitimação da Constituição está em alargar o processo democrático, a participação de amplos atores da sociedade. Igualmente fundado na escola de Frankfurt, chegou até nós o ensinamento de Hans-Georg Gadamer, pelas mãos de (Streck, 2007, p. 33), que assim resume o pensamento desta teoria, e seu fundamento interpretativo: "alinho-me aos defensores das teorias materiaissubstanciais da Constituição, porque trabalham com a perspectiva de que a implementação dos direitos fundamentais-sociais (substantivados no texto democrático da Constituição) afigura-se como condição de possibilidade da validade da própria Constituição, naquilo que ela representa de elo conteudístico que une política e direito". ${ }^{28} \mathrm{Na}$ tentativa de aclarar com mais profundidade este pensamento, leciona o (Streck, 2007, p. 33), senão observemos:

O modelo substancialista-que em parte aqui subscrevo, ressalvando sempre o problema dos ativismos judiciais, entendidos como decisionismos praticados a partir de discricionaridades interpretativas - trabalha na perspectiva de que a Constituição estabelece as condições do agir políticoestatal, a partir do pressuposto de que a Constituição é a explicitação do contrato social (contrato social também deve ser entendido a partir do paradigma hermenêutico, e não como um ponto de partido congelado). É o constitucionalismo 
dirigente que ingressa nos ordenamentos dos países após a segunda guerra. Consequentemente, é inexorável que, com a positivação dos direitos sociais fundamentais, o Poder judiciário (e, em especial, a justiça constitucional) passe a ter um papel de absoluta relevância, mormente no que diz respeitos à jurisdição constitucional..$^{29}$

Com este ponto de vista, concebe o autor o pensamento substancialista, buscado igualmente nos estudos do constitucionalismo alemão, a partir dos fundadores originais deste pensamento. Já na década de noventa, inicialmente pelas mãos do hoje Ministro do STF, Gilmar Mendes, chega até nós o ensinamento de Peter Haberle. Foi o Ministro do STF, Gilmar Mendes quem primeiramente traduziu para a língua portuguesa várias das obras da teoria alemã deste constitucionalista, fundamentalmente a "Hermenêutica Constitucional. A sociedade aberta dos interpretes da Constituição: Contribuição para a interpretação pluralista e "procedimental" da Constituição. Porto Alegre, Sergio Antonio Fabris Editores, 1997”. Queiramos ou não, talvez a explicação e o fundamento teórico da principal razão da decisão proferida pelo STF em julho de 2007 esteja nesta formulação teórica, quando não permitiu que fossem modulados os efeitos apesar de entender que deveria modificar a jurisprudência dominante da própria corte, e o que os contribuintes esperavam acontecer, isto é, que fossem modulados os efeitos, com implementação prospectiva, como o STF tem feito em inúmeras decisões. Em sua teoria, logo no início de seu estudo Haberle apresenta o que entende por tese fundamental do estágio do problema posto em relação à interpretação da Constituição. Afirma que a teoria da interpretação constitucional teria colocados até aquele momento duas questões essenciais: a) a indagação sobre as tarefas e os objetivos da interpretação constitucional; b) a indagação sobre os métodos (processo da interpretação constitucional), as (regras de procedimento). ${ }^{30}$

Afirma ainda, que não teria a teoria da interpretação constitucional conferido até aquele momento maior significado à questão relativa ao contexto sistemático em que se coloca um terceiro (novo) problema relativo aos participantes da interpretação, questão que, cumpre ressaltar, provoca a práxis em geral. Uma análise genética demonstra que existe um círculo muito amplo de participantes do processo de interpretação pluralista, processo este que se mostra muitas vezes 
difuso. Isto já seria razão significante para a doutrina tratar de maneira destacada esse tema, tendo em vista, especialmente uma concepção teórica cientifica e democrática. Diz ainda Haberle, que a teoria da interpretação constitucional esteve muito vinculada a um modelo de interpretação de uma "sociedade fechada"31. Diante desta situação propõe a seguinte tese:

No processo de interpretação constitucional estão potencialmente vinculados todos os órgãos estatais, todas as potências públicas, todos os cidadãos e grupos, não sendo possível estabelecer-se um elenco cerrado ou fixado com numerus clausus de intérpretes da Constituição. ${ }^{32}$ [...] Isso quer dizer que a teoria da interpretação deve ser garantida sob a influência da teoria democrática. Portanto, é impensável uma interpretação da Constituição sem o cidadão ativo e sem as potencias públicas mencionadas.

Na mesma linha de pensamento, mais recentemente (Leal, 2007, p, 114115), vem estudando a teoria de Haberle, e tem contribuído decisivamente para expansão e conhecimento do pensamento do principal discípulo de Konrad Hesse entre os brasileiros. Observemos como a autora ensina o pensamento de Haberle:

Tem-se, por conseguinte, que Haberle trabalha e desenvolve a questão da legitimidade a partir de uma concepção mais ampla, que pressupõe e envolve, antes, conceitos centrais como a própria noção de Constituição e de Sociedade, pressupostos e cenários dentro dos quais se desenrola a atividade hermenêutica. ${ }^{34}$

Prossegue a autora, afirmando que desta forma a Constituição se converte, então, em ordem jurídica fundamental de um processo livre e aberto, sendo que, enquanto tal, ela mesma se transmuda em um processo (permanente), o que faz com que o Direito Constitucional passe a se configurar como sendo o direito público, aberto por excelência. ${ }^{35}$ Com este apanhado teórico, entende-se que é possível analisar em termos de teoria e prática, o julgamento do STF em sede de controle de constitucionalidade, e principalmente, em atividade de 
alteração de jurisprudência reiterada e pacificada pelo pleno e por centenas de decisões monocráticas no mesmo sentido.

\section{O CONTROLE DE CONSTITUCIONALIDADE NA CONSTITUIC Ã O FEDERAL DO BRASIL - A POSSIBILIDADE DE CONFERIR EFEITOS DE MODULAÇÃO E PROSPECTIVOS À DECISÃO DO STF}

No dia 25 de junho de 2007 no julgamento do Recurso Extraordinário 370.682-SC, foi revista a jurisprudência do Supremo Tribunal Federal sobre o aproveitamento dos créditos do IPI - Imposto sobre Produtos Industrializados, e tributados com alíquota zero na entrada de insumos, que até então era favorável ao contribuinte, e com a revisão além de rever o posicionamento anterior, o STF não considerou os argumentos apresentados para estabelecer efeitos "ex tunc" à decisão, aplicando efeito "ex nunc" ao novo entendimento sufragado, impedindo a utilização dos créditos do IPI. ${ }^{36}$

Os questionamentos que o tema suscita longe estão de uma pacificação dos intérpretes do Direito, principalmente, pelos postulados contidos nas Leis no. 9.868/99 (artigo 27) e 9.882/99 (artigo 11), que outorgaram a possibilidade de graduação dos efeitos temporais das decisões judiciais, em nome da segurança jurídica ou do excepcional interesse social, quando à eficácia e aplicação das normas legais. A segurança jurídica representa para a sociedade o direito à estabilidade das relações jurídicas com a garantia de tranquilidade que as pessoas desejam e a certeza de que essas relações não serão alteradas numa previsibilidade que as deixem instáveis e inseguras no cumprimento de obrigações tributarias, principalmente quanto ao direito adquirido, $\mathrm{o}$ ato jurídico perfeito e a coisa julgada. ${ }^{37}$ A declaração de inconstitucionalidade de uma lei ou ato normativo, em nosso ordenamento jurídico, pode

36 EMENTA do Acórdão proferido Pelo Supremo Tribunal Federal em Julgamento de 25 de junho de 2007 nos autos do Recurso Extraordinário n. 370.682-SC: Relator originário: Ilmar Galvão. Relator para o Acórdão: Ministro Gilmar Mendes (artigo 38, IV, b do RISTF). Recorrente: União. Recorrido: Indústria de Embalagens Plásticas Guará Ltda. EMENTA. Recurso extraordinário. Tributário. 2. IPI. Crédito Presumido. Insumos sujeitos à alíquota zero ou não tributados. Inexistência. 3. Os princípios da não cumulatividade e da seletividade não ensejam direito de crédito presumido de IPI para o contribuinte adquirente de insumos não tributados ou sujeitos a alíquota zero. 4. Recurso extraordinário provido. ACORDAO. Vistos, relatados e discutidos estes autos, acordam os Ministros do Supremo Tribunal Federal, em Sessão Plenária, sobre a presidência da Senhora Ministra Ellen Gracie, na conformidade da ata de julgamento e das notas taquigrafadas, por unanimidade, conhecer do recurso e, por maioria, dar-lhe provimento. Na sequência do julgamento, conhecer da questão de ordem suscitada pelo Senhor Ministro Ricardo Lewandowski, no sentido de examinar a possibilidade de modular temporalmente a decisão, dando-lhe efeito prospectivo. Por maioria, em caráter excepcional, renovar a oportunidade de sustentação oral, relativamente a questão nova. No mérito, por maioria, rejeitar a questão de ordem. Brasília, 25 de junho de 2007.

37 MARTINS, Ives Gandra da Silva; RODRIGUES, Marilene Talarico Martins. Efeitos das Decisões do STF, em Matéria Tributária, em Situações de Mudança de Jurisprudência (Créditos de IPI, nas Hipóteses de Alíquota Zero). in Revista Dialética. São Paulo, 11². Volume. 2007, p. 184. 
acontecer em sede de ação direta, no controle concentrado de constitucionalidade ou diante de um caso concreto, quando se tem o controle difuso. Em ambos os casos a regra geral é a de que a decisão produza efeitos retroativos, isto é, "ex tunc". Esse entendimento prevaleceu desde o julgamento da Ação Direta de Inconstitucionalidade no. $21 / 600 .^{38}$

Com o advento da Lei no. 9.868, de 10 de novembro de 1999, que disciplinou o processo de julgamento da ação direta de inconstitucionalidade e da ação declaratória de constitucionalidade, perante o Supremo Tribunal Federal, e da Lei no. 9.882, de 3 de dezembro de 1999, que disciplina o processo de julgamento da arguição de descumprimento de preceito fundamental, nos termos do parágrafo $1^{\circ}$. Do artigo 102 da CF. Essa regra geral de interpretação quanto aos efeitos das decisões da Suprema Corte não se faz de forma automática para retroagir, "ex tunc", toda e qualquer decisão de inconstitucionalidade ou de descumprimento de preceito fundamental. Referidas leis autorizam a possibilidade de serem modulados os efeitos temporais das decisões de inconstitucionalidade, com efeitos "ex nunc" em nome da segurança jurídica ou do excepcional interesse social. ${ }^{39}$ Segundo o art. 27 da Lei ${ }^{\circ}$. 9.868/99, ao declarar a inconstitucionalidade de lei ou ato normativo, e tendo em vista razões de segurança jurídica ou de excepcional interesse social, poderá o Supremo Tribunal Federal, por maioria de dois terços de seus membros, restringir os efeitos daquela declaração ou decidir que ela só tenha eficácia a partir de seu trânsito em julgado ou de outro momento que venha a ser fixado. Igualmente, segundo o artigo 11 da Lei 9882/99 ao declarar a inconstitucionalidade de lei ou ato normativo, no processo de arguição de descumprimento de preceito fundamental, e tendo em vista razoes de segurança jurídica ou de excepcional interesse social, poderá o Supremo Tribunal Federal, por maioria de dois terços de seus membros, restringir os efeitos daquela declaração ou decidir que ela só tenha eficácia a partir de seu trânsito em julgado ou de outro momento que venha ser fixado. Desta forma as duas Leis autorizam os efeitos prospectivos, das decisões do Supremo Tribunal Federal, nos casos específicos. ${ }^{40}$ Ainda, perseguindo os apontamentos de Martins, tem-se que:

O Ministro Gilmar Mendes admitindo que em grande parte das situações, principalmente nas questões tributárias em que o Estado, e não o contribuinte, se tivesse beneficiado de leis 
inconstitucionais por ele propostas, não poderia ser favorecido com eficácia "ex nunc", e um dos coautores deste estudo entendendo que, em determinadas circunstâncias, a irreversibilidade da decisão tornaria a sua eficácia, atual ou futura, possível de ser estabelecida pelo Pretório Excelso, com o que a decisão valeria a partir de sua publicação ou para um provir determinado. ${ }^{41}$

Igualmente, não existe segundo o autor acima, qualquer impedimento a que, em controle difuso de constitucionalidade, possa a Suprema Corte, adotar o principio incluído no Direito Germânico de que, para determinadas situações e em face da lesão gravíssima à estabilidade das instituições ou à irreversibilidade das relações antes asseguradas, possa adotar-se à eficácia "ex nunc" e não "ex tunc" das decisões pretorianas. ${ }^{42} O$ expediente foi utilizado em diversas ocasiões pelo STF, como no RE 105.789 - MG; 122.202 - MG; 197.917-8 de São Paulo; 300.343-7 de São Paulo. Neste sentido, é possível a determinação de eficácia "prospectiva" em situações especiais, tendo em conta não só a irreversibilidade das relações ou situações decorrentes de orientação anterior ou ainda em gravíssima lesão a direitos patrimoniais elou fundamentais, como também os princípios da "não - surpresa", ou "da responsabilidade confiabilidade na orientação oficial", princípios essenciais para a estabilidade das instituições ${ }^{43}$. O STF, por seu Plenário, em decisão de 18 de dezembro de 2002, no RE 350.446-1, entendeu que, nas operações tributadas com a base da alíquota zero, o contribuinte do IPI teria direito de creditar-se dos valores recolhidos a este título nas operações anteriores, a exemplo do que ocorreu nos casos de isenção (RE $n^{\circ}$. 212.484). A partir da decisão proferida, diversos recursos extraordinários com o mesmo objeto, interpostos pela União Federal, passaram a ser apreciados monocraticamente pelos Ministros, com base no artigo 557 do CPC, não conhecendo do Recurso. No entanto, por circunstâncias ligadas ao sistema processual legal, a União Federal continuou apresentando seus Recursos. ${ }^{44}$

Chama a atenção ainda o autor, que num quadro de estabilidade e pacificação de jurisprudência, para dar efetividade a uniformização das decisões em nome da segurança jurídica, existem na legislação infraconstitucional diversos dispositivos destinados a evitar a proliferação de discussões judiciais de matérias sobre as quais já haja entendimento pacífico do Supremo Tribunal Federal, como antes 
referido. Diante de todos estes precedentes, os contribuintes agiram em conformidade com a orientação da Suprema Corte, quanto ao procedimento do crédito do IPI à alíquota zero, até porque a decisão foi do Plenário do Tribunal $l^{45}$, surtida efeitos “erga omnes”. Tal situação permaneceu na Suprema Corte até que o Ministro Maurício Corrêa, após indeferir monocraticamente o RE 353.657, reconsiderou sua posição em 16 de maio de 2003. Após sua aposentadoria, o processo foi redistribuido ao Ministro Marco Aurélio. Levado o caso ao Plenário, juntamente com os REs no. 350.446, 357.277 e 370.682, após alguns pedidos de vistas, foi afinal decidido pela Suprema Corte para dar provimento aos recursos da União Federal e, consequentemente, pela alteração do entendimento anterior, favorável ao contribuinte. ${ }^{46}$ É certo, entanto, que o STF, assim como qualquer outro juízo ou tribunal, não está impedido de modificar sua posição sobre determinada questão, seja para readaptar a novos fatos, seja para rever sua posição interpretação anterior. Ao fazê-lo, porém, o STF a exemplo dos demais poderes públicos, está vinculado ao princípio constitucional da segurança jurídica por força do qual a posição jurídica dos contribuintes, que procederam em conformidade com a orientação anteriormente adotada pela Suprema Corte em relação a matéria, deve ser preservada. ${ }^{4}$ Segundo o Autor, a melhor forma de conciliação da modificação do entendimento da Suprema Corte com o respeito ao conteúdo do princípio da segurança jurídica seria, pois, reconhecer à nova orientação eficácia "ex nunca". A questão envolve, segundo o autor, coerência nas decisões, proporcionalidade e razoabilidade nas mudanças e não- imposição retroativa de ônus imprevistos, em relação aos direitos fundamentais do contribuinte. ${ }^{48}$

Merece ainda destaque a questão de ordem levantada, no seguinte trecho do voto proferido pelo Ministro Ricardo Lewandowski nos REs 353.657/PR e 370.682/SC: "Como a inconstitucionalidade pode ser arguida a qualquer tempo, não é dificil imaginar que a adição sistemática da sanção de nulidade acarretaria graves transtornos as relações sociais, vista que a própria certeza do direito poderia se colocada em xeque. A anulação da norma inconstitucional, com a modulação dos efeitos temporais da decisão, surge assim como precioso instrumento que permite temperar o princípio da supremacia constitucional com outros valores socialmente relevantes, em especial o da segurança jurídica". A questão de ordem então levantada pelo 
Ministro Lewandowski, entretanto, não foi acolhida pelo Tribunal Pleno da Suprema Corte. A revisão da jurisprudência do STF sobre a questão, no julgamento da seção plenária de 25 de junho de 2007, entretanto, não considerou os argumentos apresentado para estabelecer efeitos "ex nunc" à decisão, aplicando efeitos "ex tunc" ao novo entendimento sufragado pelo Tribunal, com relação à impossibilidade de creditamento, pelos contribuintes, do IPI incidente nas operações de aquisição de insumos tributados à alíquota zero, quando utilizados na industrialização de produtos cuja saída é regularmente tributada por este imposto. ${ }^{49}$ Importante a lição de (Derzi, 2007, p. 299), ao afirmar: "é que tal decisão, sem ter havido qualquer mudança no texto da Constituição ou da Lei, alterou entendimento anterior da mesma Corte que, no RE no. 350.446-PR (Pleno) concedera o direito ao creditamento do IPI, relativo às aquisições de insumos sujeitos à alíquota zero". ${ }^{\circ}$

\section{CONCLUSÃO}

Contra o voto vencido do Ministro Lewandowski, a Corte não reconheceu, no caso em tela, confiança a ser protegida, nem direito a segurança ou a irretroatividade da nova decisão, ao argumento de que nenhuma sentença anterior, relativa à alíquota zero, chegara a transitar em julgado $^{51}$. Em magistral conclusão, ficam as seguintes indagações:

Essa primeira aproximação, em recurso de fundo tributário, feita pelo STF, parece colocar, em primeiro plano, a ideia de que uma jurisprudência somente se consolida se houver trânsito em julgado, ainda, que, reiteradamente, decisões plenárias ou monocráticas se sucedam no mesmo e idêntico sentido, durante largo período de tempo. Mas ela deixa ainda sem reposta uma plêiade de indagações, a saber, se a segurança jurídica envolveria o princípio da irretroatividade das decisões judiciais de forma objetiva, como continuidade da norma judicial que regia os fatos no tempo em que ocorreram, sendo nesse caso essencial o trânsito em julgado? Haveria diferenciação no tratamento da questão pelo Tribunal, se o principio invocado fosse restrito a proteção da confiança (que tem nuance subjetiva, embora objetivada), ou a boa-fé, na hipótese concreta daqueles contribuintes que tiveram, em seus processos, decisões monocráticas de ministros da Corte, confirmatórios da definitividade do entendimento eu os 
beneficiava? Enfim, o STF não parece ter estabelecido nenhuma discriminação entre tais princípios (segurança, irretroatividade, proteção da confiança e da boa-fé).

Continua a autora acima: curioso observar que, em determinados casos, para a Corte foi totalmente desnecessário investigar a existência de trânsito em julgado, inexistindo mesmo decisão de mérito ou sentença. Bastou a existência de simples liminar, criadora de determinada situação de fato. Não resta dúvida de que a segurança jurídica e a proteção da confiança são reconhecidas de forma mais fácil, pela Corte Superior, quando estão envolvidos atos administrativos ou legislativos. No sentido contrário da decisão, o texto legal mais antigo localiza-se no notável Código Tributário Nacional, que, editado na década de 1960, já estabelecera, no artigo 100, parágrafo único, que a observância pelo contribuinte das normas complementares administrativas como decretos, instruções normativas, práticas reiteradas, decisões com efeitos normativos, "exclui a imposição de penalidade, a cobrança de juros de mora e a atualização do valor monetário da base de cálculo". E ainda, se tiver havido um ato administrativo individual e concreto em relação a determinado contribuinte, dispõe o art. 146 do mesmo Código, que "a modificação introduzida de ofício ou em consequência de decisão administrativa ou judicial, nos critérios jurídicos adotados pela autoridade administrativas no exercício do lançamento somente pode ser efetuada, em relação a um mesmo sujeito passivo, quanto a fato gerador ocorrido posteriormente a sua introdução". ${ }^{5}$

Decorre, pois, que o STF precisa tomar cuidado para que suas decisões "políticas" não tragam a insegurança sentida pelo povo alemão ao rechaçar a teoria de Carl Schmitt, de flagrante apoio ao regime repudiado, para ficar com a de Kelsen, que exigia um comportamento jurídico do Tribunal Constitucional, e de independência do governo. Mais que isso, uma jurisdição constitucional aberta deve ouvir o conjunto dos atores sociais e culturais, o que não aconteceu na decisão analisada neste artigo.

\section{REFERÊNCIA BIBLIOGRAFICA}

ALFONSÍN, Marcelo Alberto López. Sobre el principio de supremacía y una pregunta reiterada: ?Quién debe ejercer el control de constitucionalidad en Argentina?. in: artigo oferecido pelo 
professor para estudos por ocasião das aulas do 3o. Módulo do Curso de Doutorado na UBA

BARROS CARVALHO, Paulo. Direito Tributário, Linguagem e Método. São Paulo. Editora Noeses, 2008.

COSTA, Pietro. Soberania, Representação, Democracia. Ensaios de História do Pensamento Jurídico. Curitiba: Juruá, 2010.

DERZI, Mizabel Abreu Machado. A Irretroatividade do Direito, a Proteção da Confiança, a Boa-fé e o RE no. 370.682 - SC. in Revista Dialética. São Paulo, 11. Volume. 2007.

EMENTA do Acórdão proferido Pelo Supremo Tribunal Federal em Julgamento de 25 de junho de 2007 nos autos do Recurso Extraordinário $n^{\circ}$. 370.682-SC: Relator originário: Ilmar Galvão. Relator para o Acórdão: Ministro Gilmar Mendes (artigo 38, IV, b do RISTF). Recorrente: União. Recorrido: Indústria de Embalagens Plásticas Guará Ltda. EMENTA. Recurso extraordinário. Tributário. 2. IPI. Crédito Presumido. Insumos sujeitos à alíquota zero ou não tributados. Inexistência. 3. Os princípios da não cumulatividade e da seletividade não ensejam direito de crédito presumido de IPI para o contribuinte adquirente de insumos não tributados ou sujeitos a alíquota zero. 4. Recurso extraordinário provido. ACORDÃO. Vistos, relatados e discutidos estes autos, acordam os Ministros do Supremo Tribunal Federal, em Sessão Plenária, sobre a presidência da Senhora Ministra Ellen Gracie, na conformidade da ata de julgamento e das notas taquigrafadas, por unanimidade, conhecer do recurso e, por maioria, dar-lhe provimento. Na sequência do julgamento, conhecer da questão de ordem suscitada pelo Senhor Ministro Ricardo Lewandowski, no sentido de examinar a possibilidade de modular temporalmente a decisão, dando-lhe efeito prospectivo. Por maioria, em caráter excepcional, renovar a oportunidade de sustentação oral, relativamente a questão nova. No mérito, por maioria, rejeitar a questão de ordem. Brasília, 25 de junho de 2007.

FERREYRA, Raul Gustavo. Fundamentos Constitucionais. 2a. edição - Ciudad Autónoma de Buenos Aires: Ediar, 2015.HÀBERLE, Peter. Os Problemas da Verdade no Estado Constitucional. Tradução de Urbano Carvelli. Porto Alegre, Sergio Antonio Fabris Editor, p. 22 
HÀBERLE, Peter. Traduzido por Gilmar Mendes. Hermenêutica Constitucional. A sociedade aberta dos interpretes da Constituição: Contribuição para a interpretação pluralista e "procedimental" da Constituição. Porto Alegre, Sergio Antonio Fabris Editores, 1997.

HESSE, Konrad. 2 A força normativa da Constituição. Tradução de Gilmar Ferreira Mendes. Porto Alegre, Sergio Fabris Editores, 1991.

LASSALE, Ferdinand. A Essência da Constituição. Rio de Janeiro, Editora Lumen Juris, 2000.

LEAL, Mônia C. Hennig. Jurisdição Constitucional Aberta. Reflexões sobre a Legitimidade e os Limites da Jurisdição Constitucional na Ordem Democrática. Rio de Janeiro, Editora Lumen Juris. 2007.

LEAL, Rogério Gesta. O Estado-Juiz na Democracia Contemporânea. Uma Perspectiva Procedimentalista, Porto Alegre, 2007.

LASKI, Harold J. The American Democracy. A Commentary and an Interpretation. London: George Allen and Unwin Ltd, 1949.

MARTINS, Ives Gandra da Silva; RODRIGUES, Marilene Talarico Martins. Efeitos das Decisões do STF, em Matéria Tributária, em Situações de Mudança de Jurisprudência (Créditos de IPI, nas Hipóteses de Alíquota Zero). in Revista Dialética. São Paulo, $11^{\circ}$. Volume. 2007,

MENDES, Gilmar. Jurisdição Constitucional. O Controle abstrato de Normas no Brasil e na Alemanha. São Paulo, Editora Saraiva, $3 a$. Edição, 1999.

NINO, Carlos Santiago. Una Teoría de la Justicia para la Democracia. Hacer justicia, pensar la igualdad y defender libertades. Ia. edición. Buenos Aires: Siglo Veintiuno Editores, 2013.

RADBRUCH, Gustav. Arbitrariedad Legal y Derecho Supralegal. Título original em alemán: Gesetzliches Umbrecht und Übergesetzliches Recht. Tradución de Maria Isabel Azareto de Vásquez. Publicado em "Süddeutsche Juristen Zeitung", no. 5 (agosto de 1946) Incluido posteriormente em la la. edición de "Filosofia del Derecho" de Gustav Radbruch. Impresso na Argentina por Abeledo-Perrot, 
STRECK, Lenio Luiz. Verdade e Consenso. Constituição, Hermenêutica e Teorias Discursivas da Possibilidade à Necessidade de Respostas Corretas em Direito. Rio de Janeiro, Editora Lumen Juris, 2007.

TOCQUEVILLE, Alexis de. La Democracia en America. México: Fundo de Cultura Económica, 1978. 